\title{
Methyl- $\beta$-Cyclodextrin Impairs the Monocyte-Adhering Ability of Endothelial Cells by Down-Regulating Adhesion Molecules and Caveolae and Reorganizing the Actin Cytoskeleton
}

\author{
Meiying Ao, ${ }^{a, b, c, \#} \mathrm{Li} \mathrm{Wu},{ }^{d, \#}$ Xing Zhou, ${ }^{a}$ and Yong Chen*,a,c \\ ${ }^{a}$ Nanoscale Science and Technology Laboratory, Institute for Advanced Study, Nanchang University; Nanchang, \\ Jiangxi 330031, P. R. China: ${ }^{b}$ Department of Pharmacy, Science and Technology College, Jiangxi University \\ of Traditional Chinese Medicine; Nanchang, Jiangxi 330025, P. R. China: ${ }^{c}$ College of Life Sciences, Nanchang \\ University; Nanchang, Jiangxi 330031, P. R. China: and ${ }^{d}$ School of Basic Medical Sciences, Jiangxi University of \\ Traditional Chinese Medicine; Nanchang, Jiangxi 330025, P. R. China. \\ Received January 15, 2016; accepted March 13, 2016
}

Due to its powerful ability to deplete cholesterol from the plasma membrane of cells, methyl- $\beta$ cyclodextrin $(\mathrm{M} \beta \mathrm{CD})$ has been widely used as a putative research tool in cell biology. Recently, recruiting $\mathrm{M} \beta C D$ as an effective drug (e.g., antitumor drugs) has been developed. However, it remains unclear whether $M \beta C D$, when it enters the blood circulation as a drug, influences the functions of the endothelium, e.g., the adhesion of leukocytes to the endothelium. In this study, we found that M/CD can impair the adhesion of monocytes to the monolayer of endothelial cells by lowering the cell-surface adhesive force and expression of adhesion molecules and caveolae-related molecules on/in endothelial cells, and reorganizing the actin cytoskeleton of endothelial cells. The data imply that $\mathrm{M} \beta \mathrm{CD}$, when recruited as a drug, potentially helps to inhibit inflammation or initiation/progression of atherosclerosis since its important early step is the adhesion of circulating leukocytes (e.g., monocytes) to the endothelium.

Key words methyl- $\beta$-cyclodextrin; monocyte; endothelial cell; adhesion molecule; caveola; actin cytoskeleton

Beta-cyclodextrin $(\beta-\mathrm{CD})$ is a cyclic oligosaccharide consisting of seven $\alpha$-(1,4)-linked glucopyranose subunits. Due to its relatively low water solubility (approximately $2 \%$ weight by weight), ${ }^{1)}$ various derivatives of $\beta$-CD have been developed to significantly improve the water solubility, among which methyl- $\beta$-cyclodextrin $(\mathrm{M} \beta \mathrm{CD})$ is the one studied most intensively. $\mathrm{M} \beta \mathrm{CD}$ is well known as a putative powerful cholesterol-depleting agent and commonly used to deplete plasma membrane cholesterol from cultured mammalian cells. ${ }^{2-4)}$ $\mathrm{M} \beta \mathrm{CD}$-cholesterol complexes also can efficiently replenish cells with cholesterol as cholesterol donors. ${ }^{3,4)}$

Moreover, due to the structure of a lipophilic internal cavity surrounded by hydrophilic outer surface, $\mathrm{M} \beta \mathrm{CD}$ was applied as a drug delivery system. ${ }^{5)}$ Recently, it was found that $\mathrm{M} \beta \mathrm{CD}$ per se potentially has antitumor effects and has the possibility of being an effective antitumor drug. ${ }^{6-11)}$ However, it remains uncertain whether $\mathrm{M} \beta \mathrm{CD}$, as an anticancer drug, influences the functions of the endothelium, e.g. the adhesion of circulating leukocytes (e.g. monocytes) onto the endothelium which is an important step during inflammation or initiation/progression of atherosclerosis.

In this study, the effect of $\mathrm{M} \beta \mathrm{CD}$ on the adhesion of monocytes onto the monolayer of endothelial cells was first evaluated. Then, the effects of $\mathrm{M} \beta \mathrm{CD}$ on cell-surface adhesive force properties, expression/distribution of adhesion molecules and caveolae-related molecules, and actin cytoskeleton of endothelial cells were investigated to elucidate the potential underlying mechanisms.

\footnotetext{
${ }^{\#}$ These authors contributed equally to this work.

* To whom correspondence should be addressed. e-mail: dr_yongchen@hotmail.com
}

\section{MATERIALS AND METHODS}

Cell Culture Human umbilical vein endothelial cells (HUVECs) were purchased from Xiangya Central Experiment Laboratory (Hunan, China) and cultured in Dulbecco's modified Eagle's medium (DMEM) (Gibco, U.S.A.) supplemented with $10 \%(w / v)$ fetal calf serum (Hyclone, South Logan, UT, U.S.A), $100 \mathrm{U} / \mathrm{mL}$ penicillin, and $100 \mu \mathrm{g} / \mathrm{mL}$ streptomycin. For all experiments, cell cultures had been passaged approximately 5 times.

3-(4,5-Dimethylthiazol-2-yl)-2,5-diphenyltetrazolium bromide (MTT) Assay MTT assay was performed as reported previously. ${ }^{12)}$ Approximately $8 \times 10^{3}$ HUVECs were plated in each well of a 96 -well plate and cultured at $37^{\circ} \mathrm{C}$ in a $5 \% \mathrm{CO}_{2}$ incubator for $24 \mathrm{~h}$. After washing with phosphate buffered saline (PBS), cells in different wells were treated with different concentrations $(0,5,10,20 \mathrm{~mm})$ of $\mathrm{M} \beta \mathrm{CD}$ (Sigma, U.S.A.) for $30 \mathrm{~min}$ at $37^{\circ} \mathrm{C}$. After PBS washes, $100 \mu \mathrm{L}$ of fresh medium and $20 \mu \mathrm{L} 5 \mathrm{mg} / \mathrm{mL}$ MTT were added to each well, and the cells were incubated for $4 \mathrm{~h}$. After reaction termination and solution removal, $100 \mu \mathrm{L}$ of dimethyl sulfoxide (DMSO) was added to each well, and the plate was shaken gently at $37^{\circ} \mathrm{C}$ for $10 \mathrm{~min}$. The absorbance (optical density) was measured at $578 \mathrm{~nm}$ with a microplate reader (Rayto).

Monocyte Adhesion Assay Celltracker C34552 (Invitrogen, U.S.A.) was utilized to stain THP-1 cells for $c a$. $30 \mathrm{~min}$ at $37^{\circ} \mathrm{C}$ according to the manufacturer's instruction. The cells were washed twice with serum-free medium to remove excess dyes. Then the cells were added onto the confluent monolayer of HUVECs pretreated with or without 1,5 , and $10 \mathrm{~mm}$ $\mathrm{M} \beta \mathrm{CD}$ for $30 \mathrm{~min}$ at $37^{\circ} \mathrm{C}$ and incubated for $2 \mathrm{~h}$ at $37^{\circ} \mathrm{C}$. After washing twice with PBS to remove the unattached cells, the samples were observed under a confocal microscope. The 
excitation and emission wavelengths for Celltracker C34552 were 577 and $602 \mathrm{~nm}$, respectively. The number of attached fluorescently-stained THP-1 cells in each field was counted.

Adhesive Force Mapping by Atomic Force Microscopy (AFM) The living HUVECs treated with or without $10 \mathrm{~mm}$ $\mathrm{M} \beta \mathrm{CD}$ for $30 \mathrm{~min}$ at $37^{\circ} \mathrm{C}$ were immediately detected by Agilent series 5500 AFM in contact mode. The adhesive force mapping of an area of $30 \times 30 \mu \mathrm{m}$ on the cell surface was performed. The length and width of the AFM cantilevers were 200 and $28 \mu \mathrm{m}$, respectively, with a resonant frequency of $77 \mathrm{kHz}$ and a spring constant of $c a .0 .04 \mathrm{~N} / \mathrm{m}$.

Confocal Microscopy and Flow Cytometry For fluorescence imaging, an LSM710 confocal microscope (Carl Zeiss, Oberkochen, Germany) equipped with a Zeiss inverted microscope and a Zeiss Plan-Neofluar objective $(40 \times / 0.75)$ was recruited. Flow cytometric acquisition and analysis were performed in a FACSCalibur flow cytometer (BD Biosciences, U.S.A.).

Fluorescence Staining of Adhesion Molecules, Caveolin-1, and Phosphatidylinositol 4,5-Bisphosphate (PIP $)$ The fluorescence staining of each molecule was performed according to the manufactory provided protocol. Briefly, the cells pre-treated with or without $\mathrm{M} \beta \mathrm{CD}$ for $30 \mathrm{~min}$ at $37^{\circ} \mathrm{C}$ were fixed with $4 \%$ paraformaldehyde for $20 \mathrm{~min}$ at room temperature, washed with PBS (for adhesion molecules and caveolin-1) or Tris-buffered saline (TBS); for $\mathrm{PIP}_{2}$ ) two times, and then subjected to fluorescence staining.

For the surface staining of intercellular adhesion molecule 1 (ICAM-1), the fixed cells were incubated with phycoerythrin (PE)-conjugated anti-human CD54 (eBioscicence, CA, U.S.A.) at a final concentration of $5 \mu \mathrm{g} / \mathrm{mL}$ in PBS for $1 \mathrm{~h}$ at $37^{\circ} \mathrm{C}$. After washing with PBS three times, the samples were subjected to flow cytometry.

For caveolin-1 staining, the fixed cells were incubated with $5 \mu \mathrm{g} / \mathrm{mL}$ rabbit anti-caveolin-1 (Abcam, London, U.K.) in PBS plus $0.05 \%$ saponin for $1 \mathrm{~h}$ at $37^{\circ} \mathrm{C}$ and then with Pacific blueconjugated goat anti-rabbit immunoglobulin G (IgG) (Life Technologies, U.S.A.) in PBS $(1: 1000)$ for $30 \mathrm{~min}$ at $37^{\circ} \mathrm{C}$. After washing with PBS three times, the samples were subjected to confocal microscopy and flow cytometry.

For $\mathrm{PIP}_{2}$, the intracellular staining was performed as reported previously. ${ }^{13)}$ The fixed cells were permeabilized with $0.5 \%$ saponin for $15 \mathrm{~min}$ at room temperature, washed three times with TBS, and blocked with $1 \%$ bovine serum albumin (BSA) in TBS over night at $4^{\circ} \mathrm{C}$. Then, the cells were stained with biotinylated mouse anti-PIP ${ }_{2}$ IgM (Echelon Biosciences, UT, U.S.A.) at a final concentration of $10 \mu \mathrm{g} / \mathrm{mL}$ in TBS for $1 \mathrm{~h}$ at $37^{\circ} \mathrm{C}$ and subsequently with streptavidin-conjugated Alexa Fluor 555 (Life Technologies, U.S.A.) in TBS for $30 \mathrm{~min}$ at $37^{\circ} \mathrm{C}$. After washing thoroughly with distilled water, the cells were subject to confocal microscopy and flow cytometry.

Visualization and Quantification of Actin Cytoskeleton HUVEC Cells were plated in petri dishes and cultured in the incubator $\left(37^{\circ} \mathrm{C}, 5 \% \mathrm{CO}_{2}\right)$ for $24 \mathrm{~h}$ to reach a $70 \%$ confluence. After treated with or without $10 \mathrm{~mm} \mathrm{M} \beta \mathrm{CD}$ for $30 \mathrm{~min}$ at $37^{\circ} \mathrm{C}$, the cells were fixed by $4 \%$ paraformaldehyde for $20 \mathrm{~min}$, washed three times with $\mathrm{PBS}$, and stained by anti-paxillin monoclonal antibody (mAb) (overnight at $4^{\circ} \mathrm{C}$; Abcam) plus Alexa fluor 488 goat anti-mouse $\operatorname{IgG}$ (for $2 \mathrm{~h}$ at $37^{\circ} \mathrm{C}$ ) and tetramethylrhodamine (TRITC)-Phalloidin (for $1 \mathrm{~h}$ at room temperature; Sigma) as usual. After washing twice with

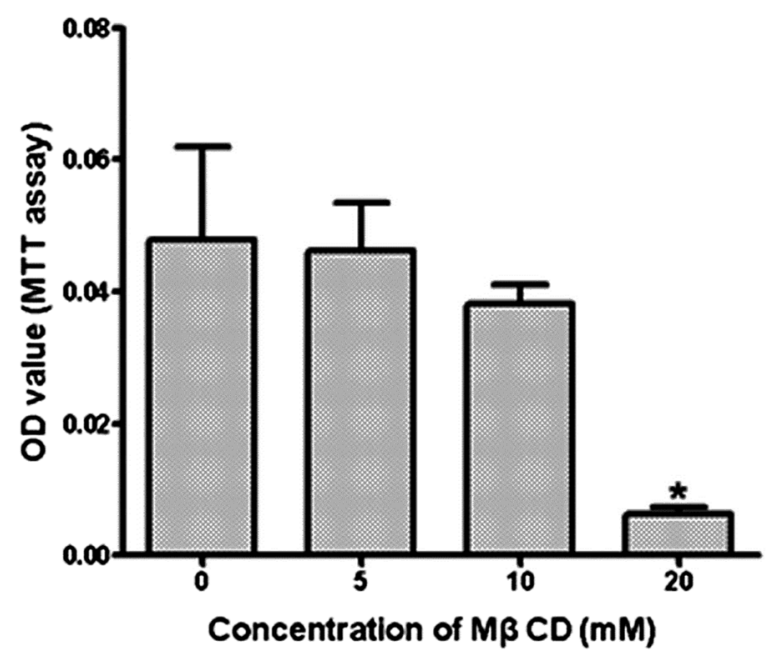

Fig. 1. MTT Assay Detects the Effects of $\mathrm{M} \beta \mathrm{CD}$ at Different Concentrations on the Viability of HUVECs

PBS, the cells were observed under the confocal microscope. The excitation/emission wavelengths for Alexa fluor 488 and TRITC were $488 \mathrm{~nm} /(493-630 \mathrm{~nm})$ and $561 \mathrm{~nm} /(570-670 \mathrm{~nm})$, respectively. The length of each fluorescently labeled actin filament was measured using the Zeiss LSM 710 Zen software.

Cell Spreading Assay Spread area-based spreading assay was performed as reported previously. ${ }^{14,15)}$ Briefly, HUVECs at $70 \%$ confluence were treated with or without $10 \mathrm{~mm} \mathrm{M} \beta \mathrm{CD}$ for $30 \mathrm{~min}$ at $37^{\circ} \mathrm{C}$. The cells were then fixed by $4 \%$ paraformaldehyde, rinsed with PBS, and imaged in PBS by the confocal microscope. The spread area of each cell was extracted by planimetry via the Zeiss LSM 710 Zen software.

Statistical Analysis All graphs were made using GraphPad Prism version 5.0 (GraphPad Software, La Jolla, CA, U.S.A.) on which all data were expressed as the mean \pm standard deviation (S.D.) from at least three independent experiments. Statistical analysis was performed using Student's $t$-test. A difference was regarded as significant when $p<0.05$ (* $p<0.05 ; * * p<0.01 ; * * * p<0.001)$.

\section{RESULTS AND DISCUSSION}

The effects of $\mathrm{M} \beta \mathrm{CD}$ on the membrane alternation, cytoskeletal reorganization, proliferation, and apoptosis of endothelial cells have been intensively studied. ${ }^{16-18)}$ However, it remains unclear whether and how $\mathrm{M} \beta \mathrm{CD}$ affects the adhesion of leukocytes (e.g. monocytes) onto the endothelium which is the first step of leukocyte trans-endothelial migration.

Firstly, we studied the effects of $\mathrm{M} \beta \mathrm{CD}$ at different concentrations on the viability of HUVECs using MTT assay (Fig. 1). The data shows that the $20 \mathrm{~mm} \mathrm{M} \beta C D$ treatment for $30 \mathrm{~min}$ induced significant death of HUVECs whereas $\leq 10 \mathrm{~mm}$ $\mathrm{M} \beta \mathrm{CD}$ treatments for $30 \mathrm{~min}$ caused no statistically significant, although slight, decrease in cell viability. Therefore, in the following experiments we used $\leq 10 \mathrm{~mm} \mathrm{M} \beta \mathrm{CD}$ to treat HUVECs for $30 \mathrm{~min}$.

To test whether $\mathrm{M} \beta \mathrm{CD}$ influence the adhesion of monocytes onto endothelial cells, THP-1 cells (a putative monocyte cell line) were fluorescently stained with Celltracker, co-cultured with the monolayer of HUVEC cells (a widely used endothelial cell line) pretreated with or without 1,5 , and $10 \mathrm{~mm}$ 
$\mathrm{M} \beta \mathrm{CD}$, respectively and imaged by confocal microscopy. The confocal fluorescence images clearly show that compared with untreated HUVECs there were less THP-1 cells on the monolayer of the HUVECs treated by 5 or $10 \mathrm{~mm} \mathrm{M} \beta C D$ (Fig. 2A). It was further confirmed by the statistical analysis (Fig. 2B), implying that $\mathrm{M} \beta \mathrm{CD}$ significantly inhibited the adhesion of THP-1 cells onto HUVECs.

Since the biomechanical properties of cell surfaces may be involved in cell-cell adhesion, the cell-surface adhesive force of HUVECs treated with or without $10 \mathrm{~mm} \mathrm{M} \beta \mathrm{CD}$ was then detected by the force measurement function of AFM. The adhesive force mapping on a cell surface region of $30 \times 30 \mu \mathrm{m}$ shows that $\mathrm{M} \beta \mathrm{CD}$ can impair the cell-surface adhesive force of HUVECs (Fig. 3).

It is well known that adhesion molecules on cell surfaces are the major determinants of the adhesion of leukocytes onto the endothelium. Therefore, we then investigated the effects of $\mathrm{M} \beta \mathrm{CD}$ on the expression of ICAM-1 on HUVECs by using flow cytometry (Fig. 4). The data shows that the mean fluores- cence intensity (MFI) of ICAM-1 on HUVECs significantly decreased after treated with 5 and $10 \mathrm{~mm} \mathrm{M} \beta \mathrm{CD}$. The data implies that $\mathrm{M} \beta \mathrm{CD}$ can inhibit the expression of adhesion molecules on HUVECs in a dose-dependent manner.

Caveolae, a special type of cholesterol-enriched lipid raft, are highly abundant in endothelial cells and play multiple roles in cell adhesion and signal transduction. ${ }^{19)}$ Another important molecule $\mathrm{PIP}_{2}$ which plays a string-puller role in membranecytoskeleton coupling ${ }^{20,21)}$ is also enriched in caveolae. ${ }^{22,23)}$ Therefore, we tried to evaluate the effects of $\mathrm{M} \beta \mathrm{CD}$ on caveolae and $\mathrm{PIP}_{2}$. The data from both confocal microscopy and flow cytometry indicate that $\mathrm{M} \beta \mathrm{CD}$ also inhibited the expressions of caveolin-1 (Fig. 5), a structural protein of caveolae, and $\mathrm{PIP}_{2}$ (Fig. 6).

Finally, we sought to investigate the effects of $\mathrm{M} \beta \mathrm{CD}$ on actin cytoskeleton which is associated with plasma membrane generally via caveolae/PIP ${ }_{2}$. The data show that $\mathrm{M} \beta \mathrm{CD}$ induced significant decrease in the average length of individual actin filaments causing the decrease in the average spreading
A
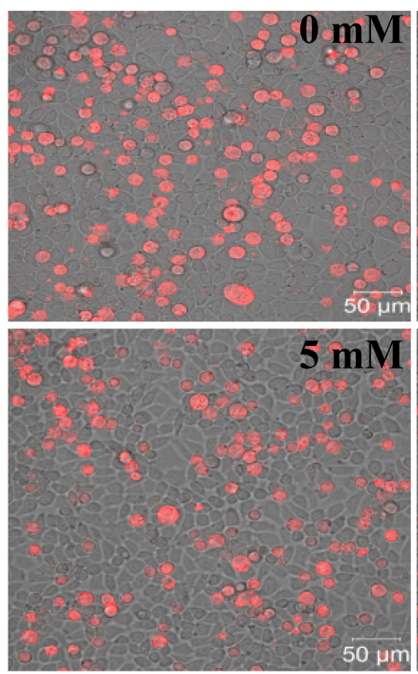
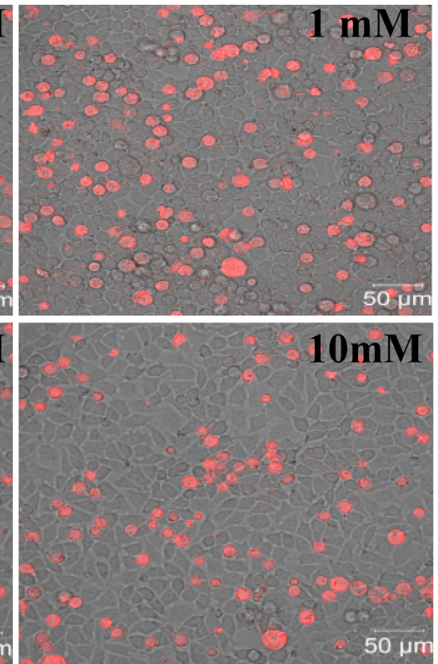

B

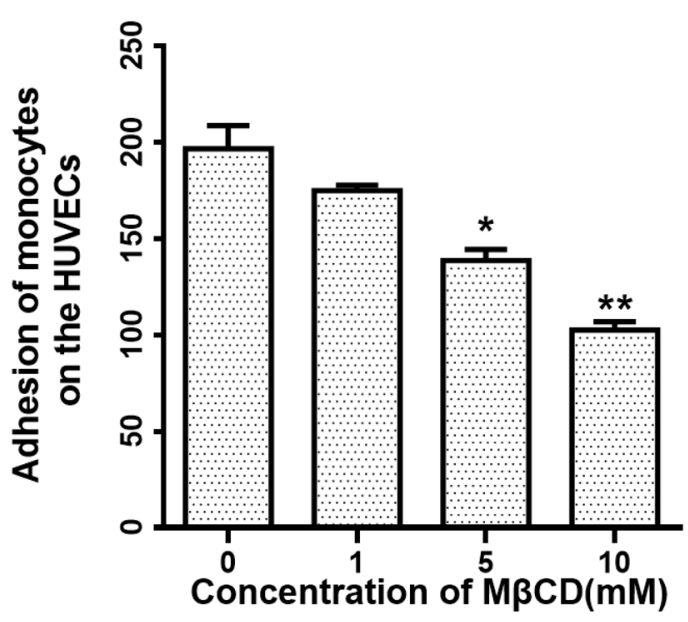

Fig. 2. $\mathrm{M} \beta \mathrm{CD}$ Impairs the Adhesion of Monocytes onto HUVECs

Celltracker C34552 was utilized to stain THP-1 cells. (A) Fluorescently stained THP-1 cells on the monolayer of HUVECs treated with $0,1,5$, and $10 \mathrm{~mm} \mathrm{M} \beta \mathrm{CD}$ for $30 \mathrm{~min}$, respectively. (B) Average numbers of THP-1 cells adhered on the monolayer of HUVECs treated with or without M $\beta C D$ in a field with the same size.
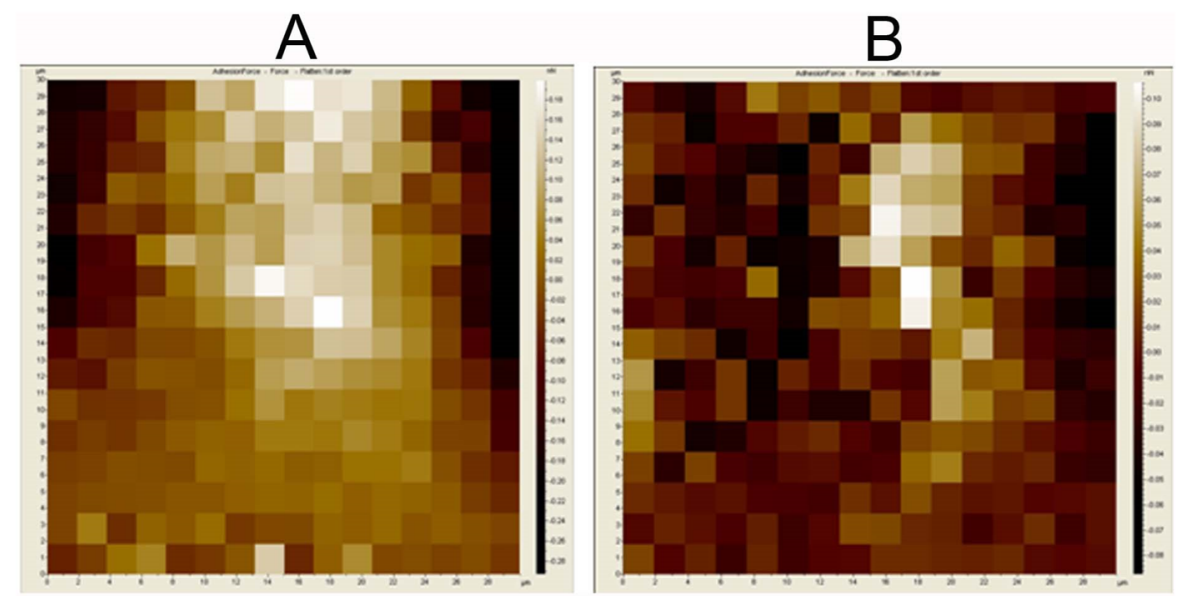

Fig. 3. $\mathrm{M} \beta \mathrm{CD}$ Lowers the Cell-Surface Adhesive Force of HUVECs

(A) Representative adhesive force mapping on an untreated cell detected by AFM. (B) Representative adhesive force mapping on a M $\beta$ CD (10 mM)-treated cell detected by AFM. Scan size: $30 \mu \mathrm{m} \times 30 \mu \mathrm{m}$. 

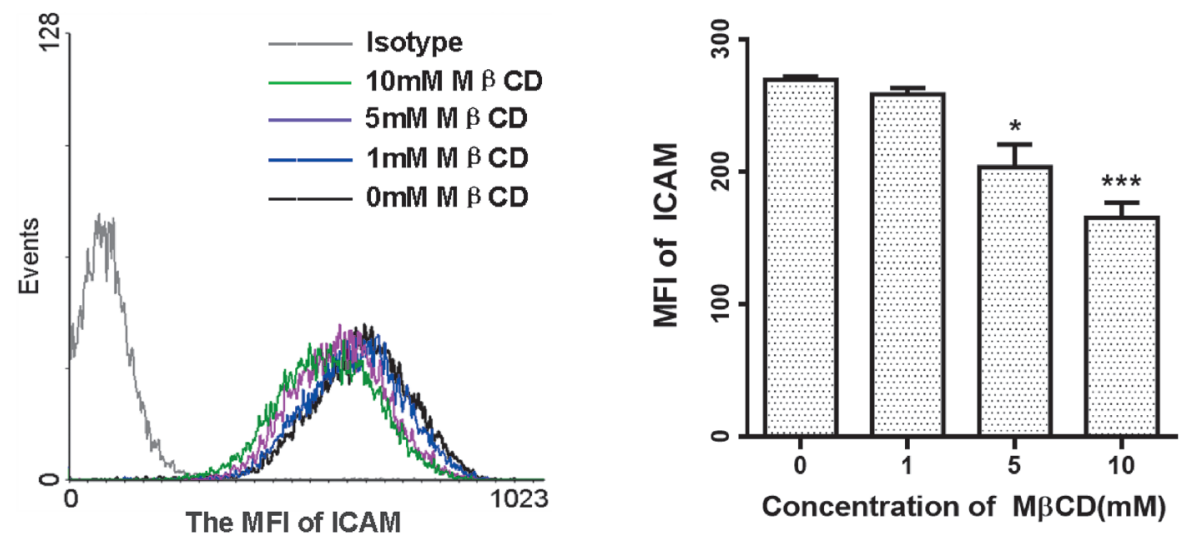

Fig. 4. $\mathrm{M} \beta \mathrm{CD}$ Inhibits the Expression of Adhesion Molecules on HUVECs

Left: representative flow cytometric data showing the effects of $\mathrm{M} \beta \mathrm{CD}$ on the mean fluorescence intensity (MFI) of fluorescently stained ICAM-1 on HUVECs. Right: quantification and statistical analyses of $\mathrm{M} \beta \mathrm{CD}$-induced changes in MFI of ICAM-1.

A
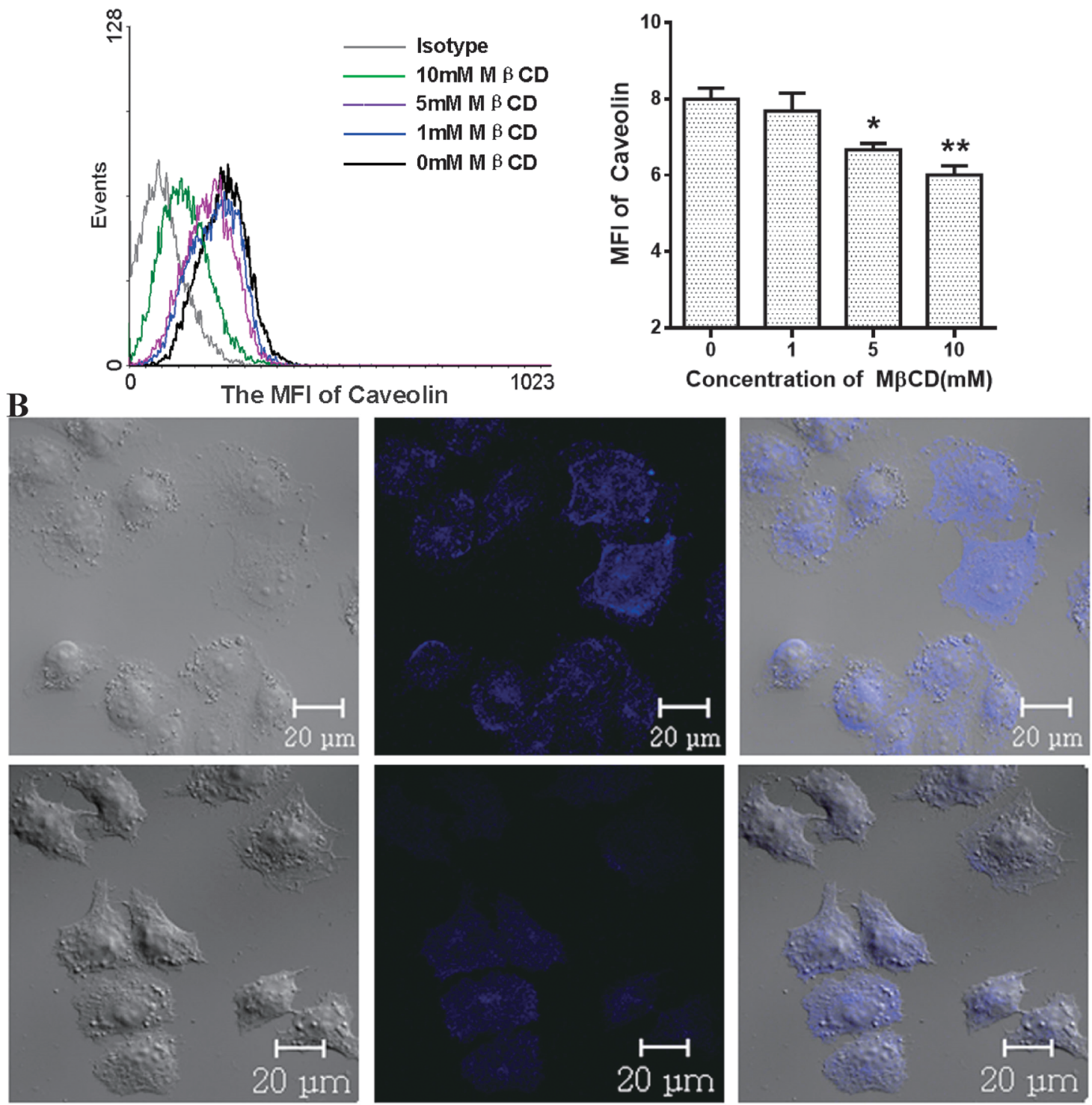

Fig. 5. $\mathrm{M} \beta \mathrm{CD}$ Inhibits the Expression of Caveolin-1 in HUVECs

(A) The representative (left) and statistical analyses (right) of flow cytometric data show that the MFI of caveolin-1 in M $\beta$ CD-treated cells was significantly lower than that on untreated cells. (B) Confocal microscopy shows that compared with untreated cells (upper panel) there were fewer caveolin-1 molecules in the treated cells by $10 \mathrm{~mm} \mathrm{M} \beta C D$ (lower panel). From left to right: DIC image, fluorescence image, and merged image, respectively. 

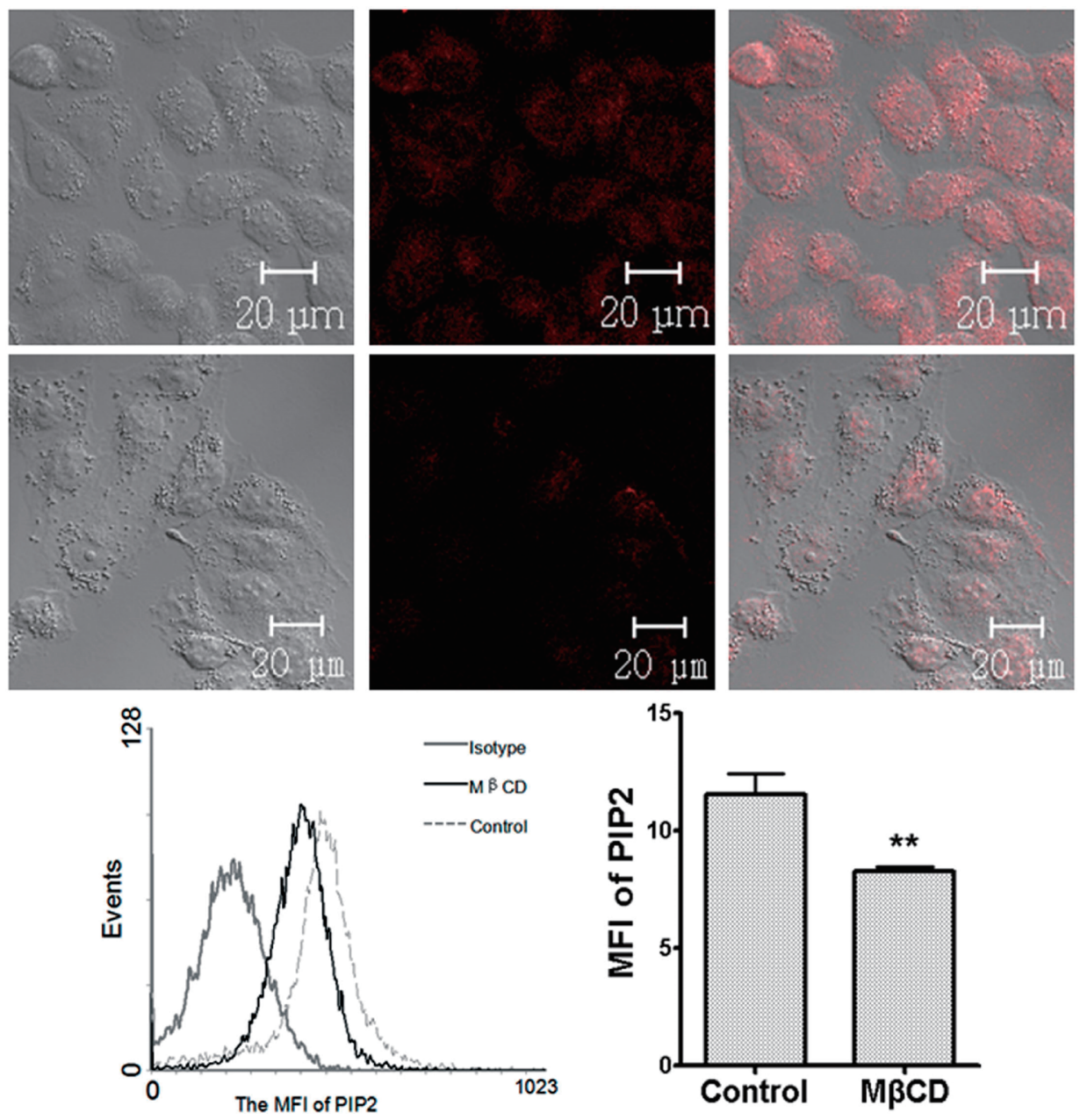

Fig. 6. $\mathrm{M} \beta \mathrm{CD}$ Inhibits the Expression of $\mathrm{PIP}_{2}$ in HUVECs

Confocal microscopy shows that compared with untreated cells (upper panel) there were fewer $\mathrm{PIP}_{2}$ molecules in the treated cells by $10 \mathrm{~mm} \mathrm{M} \beta \mathrm{CD}$ (middle panel). From left to right: DIC image, fluorescence image, and merged image, respectively. The representative (left) and statistical analyses (right) of flow cytometric data (bottom panel) show that the MFI of $\mathrm{PIP}_{2}$ on $\mathrm{M} \beta \mathrm{CD}$-treated cells was significantly lower than that on untreated cells.
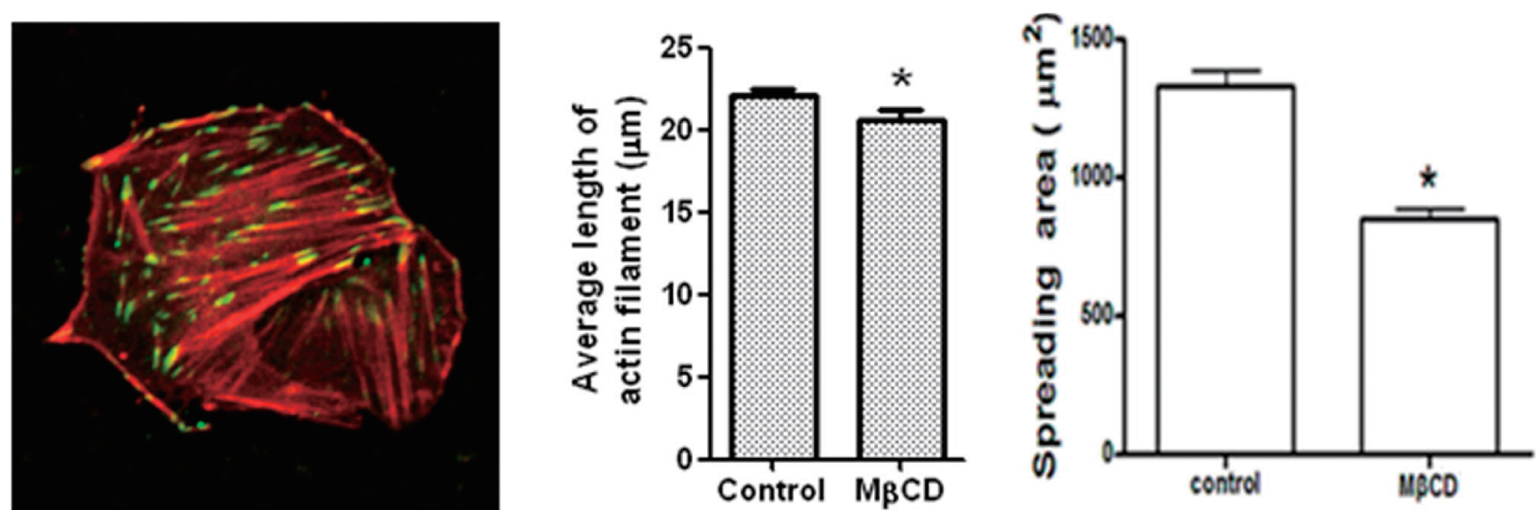

Fig. 7. $\mathrm{M} \beta \mathrm{CD}$ Causes Cytoskeletal Reorganization/Shortening

Left panel: a representative fluorescence confocal image showing actin filaments and focal adhesions at both ends of filaments by fluorescently staining F-actin (red) and paxillin (a main focal adhesion molecule; green), respectively. Middle panel: the average length of individual actin filaments in HUVECs treated with or without M $\beta C D$. Right panel: the average spreading area of individual HUVECs treated with or without $10 \mathrm{~mm} \mathrm{M} \beta \mathrm{CD}$.

area of individual HUVECs (Fig. 7). Therefore, $\mathrm{M} \beta \mathrm{CD}$ also caused cytoskeletal reorganization/shortening in HUVECs probably due to the $\mathrm{M} \beta \mathrm{CD}$-induced weakening of the caveolae/PIP ${ }_{2}$ which mediates the membrane-cytoskeleton coupling.

Taken together, in a concentration-dependent manner $\mathrm{M} \beta \mathrm{CD}$ can inhibit the adhesion of monocytes onto endothelial cells by down-regulating the cell-surface adhesive force property and the expression of adhesion molecules on endothelial cells which is probably correlated with caveolae (or lipid rafts) and cytoskeletal reorganization although it still remains controversial whether adhesion molecules (e.g. ICAM-1) are present in caveolae. ${ }^{24-28)}$ It implies that $\mathrm{M} \beta \mathrm{CD}$, when recruited 
as an anticancer drug, will impair the adhesion of circulating leukocytes (e.g. monocytes) onto the endothelium and therefore potentially help to inhibit inflammation or initiation/ progression of atherosclerosis.

Acknowledgments This study was supported by the National Natural Science Foundation of China (81560083) and the Natural Science Foundation of Jiangxi Province (20151BAB205005).

Conflict of Interest The authors declare no conflict of interest.

\section{REFERENCES}

1) Davis ME, Brewster ME. Cyclodextrin-based pharmaceutics: Past, present and future. Nat. Rev. Drug Discov., 3, 1023-1035 (2004).

2) Christian AE, Haynes MP, Phillips MC, Rothblat GH. Use of cyclodextrins for manipulating cellular cholesterol content. J. Lipid Res., 38, 2264-2272 (1997).

3) Zidovetzki R, Levitan I. Use of cyclodextrins to manipulate plasma membrane cholesterol content: Evidence, misconceptions and control strategies. Biochim. Biophys. Acta, 1768, 1311-1324 (2007).

4) Mahammad S, Parmryd I. Cholesterol depletion using methyl-betacyclodextrin. Methods Mol. Biol., 1232, 91-102 (2015).

5) Loftsson T, Duchene D. Cyclodextrins and their pharmaceutical applications. Int. J. Pharm., 329, 1-11 (2007).

6) Grosse PY, Bressolle F, Vago P, Simony-Lafontaine J, Radal M, Pinguet F. Tumor cell membrane as a potential target for methylbeta-cyclodextrin. Anticancer Res., 18 (1A), 379-384 (1998).

7) Grosse PY, Bressolle F, Pinguet F. Antiproliferative effect of methyl-beta-cyclodextrin in vitro and in human tumour xenografted athymic nude mice. Br. J. Cancer, 78, 1165-1169 (1998).

8) Onodera R, Motoyama K, Arima H. Design and evaluation of folate-appended methyl-beta-cyclodextrin as a new antitumor agent. J. Incl. Phenom. Macrocycl. Chem., 70, 321-326 (2011).

9) Onodera R, Motoyama K, Okamatsu A, Higashi T, Arima H. Potential use of folate-appended methyl-beta-cyclodextrin as an anticancer agent. Scientific Reports, 3, 1104 (2013).

10) Mohammad N, Malvi P, Meena AS, Singh SV, Chaube B, Vannuruswamy G, Kulkarni MJ, Bhat MK. Cholesterol depletion by methyl-beta-cyclodextrin augments tamoxifen induced cell death by enhancing its uptake in melanoma. Mol. Cancer, 13, 204 (2014).

11) Gotoh K, Kariya R, Alam MM, Matsuda K, Hattori S, Maeda Y, Motoyama K, Kojima A, Arima H, Okada S. The antitumor effects of methyl-beta-cyclodextrin against primary effusion lymphoma via the depletion of cholesterol from lipid rafts. Biochem. Biophys. Res. Commun., 455, 285-289 (2014).

12) Zeng F, Yang W, Huang J, Chen Y, Chen Y. Determination of the lowest concentrations of aldehyde fixatives for completely fixing various cellular structures by real-time imaging and quantification. Histochem. Cell Biol., 139, 735-749 (2013).

13) Zhao SY, Liao HH, Ao MY, Wu L, Zhang XJ, Chen Y. Fixationinduced cell blebbing on spread cells inversely correlates with phos- phatidylinositol 4,5-bisphosphate level in the plasma membrane. FEBS Open Biol., 4, 190-199 (2014).

14) Huang J, Shao WX, Wu L, Yang W, Chen Y. Effects of exogenous ganglioside GM1 on different stages of cell spreading studied by directly quantifying spreading rate. Cell Commun. Adhes., 19, 85-95 (2012).

15) Liao H, He H, Chen Y, Zeng F, Huang J, Wu L, Chen Y. Effects of long-term serial cell passaging on cell spreading, migration, and cell-surface ultrastructures of cultured vascular endothelial cells. Cytotechnology, 66, 229-238 (2014).

16) Gupta AK, Holzgreve W, Hahn SH. Decrease in lipid levels of syncytiotrophoblast micro-particles reduced their potential to inhibit endothelial cell proliferation. Arch. Gynecol. Obstet., 277, 115-119 (2008).

17) Hinzey AH, Kline MA, Kotha SR, Sliman SM, Butler ESO, Shelton AB, Gurney TR, Parinandi NL. Choice of cyclodextrin for cellular cholesterol depletion for vascular endothelial cell lipid raft studies: Cell membrane alterations, cytoskeletal reorganization and cytotoxicity. Indian J. Biochem. Biophys., 49, 329-341 (2012).

18) Wu L, Huang J, Yu XX, Zhou XQ, Gan CY, Li M, Chen Y. AFM of the ultrastructural and mechanical properties of lipid-raft-disrupted and/or cold-treated endothelial cells. J. Membr. Biol., 247, 189-200 (2014)

19) Parton RG, Simons K. The multiple faces of caveolae. Nat. Rev. Mol. Cell Biol., 8, 185-194 (2007).

20) Nebl T, Oh SW, Luna EJ. Membrane cytoskeleton: PIP2 pulls the strings. Curr. Biol., 10, R351-R354 (2000).

21) Saarikangas J, Zhao HX, Lappalainen P. Regulation of the actin cytoskeleton-plasma membrane interplay by phosphoinositides. Physiol. Rev., 90, 259-289 (2010).

22) Pike LJ, Casey L. Localization and turnover of phosphatidylinositol 4,5-bisphosphate in caveolin-enriched membrane domains. J. Biol. Chem., 271, 26453-26456 (1996).

23) Fujita A, Cheng JL, Tauchi-Sato K, Takenawa T, Fujimoto T. A distinct pool of phosphatidylinositol 4,5-bisphosphate in caveolae revealed by a nanoscale labeling technique. Proc. Natl. Acad. Sci. U.S.A., 106, 9256-9261 (2009).

24) Cordes U, Pedersen M, Bastholm L, Nielsen M, Werdelin O. Murine thymic nurse cells express ICAM-1 on caveolar and vacuolar membranes. Scand. J. Immunol., 46, 344-348 (1997).

25) Amos C, Romero IA, Schultze C, Rousell J, Pearson JD, Greenwood J, Adamson P. Cross-linking of brain endothelial intercellular adhesion molecule (ICAM)-1 induces association of ICAM-1 with detergent-insoluble cytoskeletal fraction. Arterioscler. Thromb. Vasc. Biol., 21, 810-816 (2001).

26) Romero IA, Amos CL, Greenwood J, Adamson P. Ezrin and moesin co-localise with ICAM-1 in brain endothelial cells but are not directly associated. Brain Res. Mol. Brain Res., 105, 47-59 (2002).

27) Millán J, Hewlett L, Glyn M, Toomre D, Clark P, Ridley AJ. Lymphocyte transcellular migration occurs through recruitment of endothelial ICAM-1 to caveola- and F-actin-rich domains. Nat. Cell Biol., 8, 113-123 (2006).

28) Fu C, He JL, Li CH, Shyy JYJ, Zhu Y. Cholesterol increases adhesion of monocytes to endothelium by moving adhesion molecules out of caveolae. Biochim. Biophys. Acta, 1801, 702-710 (2010). 